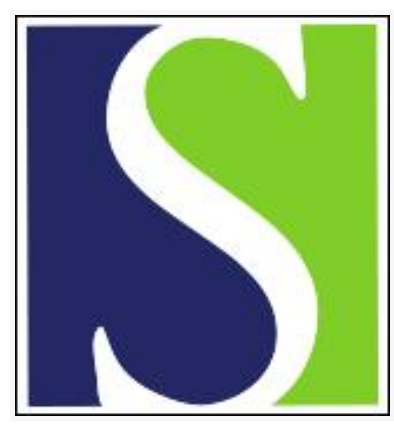

Scand J Work Environ Health 2002;28(5):341-348

https://doi.org/10.5271/sjweh.684

Issue date: Oct 2002

Cancer incidence of dry cleaning, laundry and ironing workers in Sweden

by Travier N, Gridley G, De Roos AJ, Plato N, Moradi T, Boffetta P

Affiliation: Unit of Environmental Cancer Epidemiology, International Agency for Research on Cancer, 150 Cours Albert Thomas, FR-69008 Lyon, France.

Refers to the following texts of the Journal: 1999;25 suppl 2:1-116 1995;21(4):310-312

Key terms: cancer incidence; dry cleaning worker; epidemiology; ironing worker; laundry worker; lymphohematopoietic neoplasms; occupational exposure; record-linkage study; respiratory neoplasms; Sweden

This article in PubMed: www.ncbi.nlm.nih.gov/pubmed/12432988

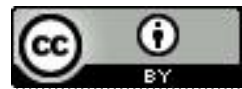




\title{
Cancer incidence of dry cleaning, laundry and ironing workers in Sweden
}

\author{
by Noemie Travier, MS, ${ }^{1}$ Goria Gidley, MS, ${ }^{2}$ Anneclaire J De Roos, $P h D,{ }^{2}$ Nils Plato, $P h D,{ }^{3}$ \\ Tahereh Moradi, PhD, 4 Paolo Boffetta, MD 1,2,4
}

\begin{abstract}
Travier N, Gidley G, De Roos AJ, Plato N, Moradi T, Boffetta P. Cancer incidence of dry cleaning, laundry and ironing workers in Sweden. Scand J Work Environ Health 2002;28(5):341-348.
\end{abstract}

\begin{abstract}
Objectives This study investigated the risk of cancer among dry cleaners, launderers, and pressers in a large record-linkage study in Sweden.

Methods The Swedish Cancer Register III contains nationwide data on cancer incidence between 1971 and 1989, by occupation and industry of employment, as reported in the 1960 and 1970 censuses. Dry cleaners, launderers, and pressers were compared with the remaining part of the employed population using multivariable Poisson regression models and standardized incidence ratios.

Results Dry cleaners, launderers, and pressers employed in the laundry, ironing, or dyeing industry in both censuses showed an increased risk of Hodgkin's disease [relative risk (RR) 2.69, 95\% confidence interval (95\% CI 1.01-7.19], an elevated risk of leukemia among women (RR 2.53, 95\% CI 1.44-4.46), and increased risks of stomach (RR 1.80, 95\% CI 1.05-3.11) and laryngeal (RR 2.42, 95\% CI 0.91-6.45) cancers among men. The results of the analyses of launderers and dry cleaners as a separate occupational group reflected those of the whole exposure group, while pressers showed an elevated lung cancer risk (RR 1.67, 95\% CI 0.75-3.72).

Conclusions If they are not due to chance or confounding, the results of this study reflect either the potentiation of other carcinogens by solvents or direct effects. The results are limited by the use of job and industry titles as proxies for occupational exposures.
\end{abstract}

Key terms epidemiology, lymphohematopoietic neoplasms, occupational exposure, record-linkage study, respiratory neoplasms.

Workers engaged in dry cleaning and laundering are frequently exposed to organic solvents (1) through skin absorption, eye contact, and inhalation. Before 1960, Stoddard solvent, carbon tetrachloride, and trichloroethylene (TCE) were primarily used. The use of perchloroethylene (PCE) increased after 1950 but was replaced in up to $50 \%$ of uses by chlorofluocarbons (CFC) in the early 1980s. TCE and PCE are classified by the International Agency for Research on Cancer as probably carcinogenic to humans (group 2A) (1). At the end of the dry-cleaning cycle (which includes the three basic steps of washing, solvent extraction, and dying), clothes are removed from the dryer, examined for any remaining stains, and pressed (1). Therefore, especially in dry-cleaning shops where all operations are carried out in a single room, the pressers may be, along with the cleaning machine operators, exposed to solvents. However, the exposure of pressers to solvents is likely to be lower than that of the machine operators (2).

The relationship between employment in dry cleaning and the occurrence of cancers has been assessed in epidemiologic cohort studies since 1979 (3). The most consistent results have been obtained for esophageal and bladder cancers. For esophageal cancer, increased risks (on the order of twofold) were found in two cohorts of dry cleaners in the United States (US) $(4,5)$ and in an

1 Unit of Environmental Cancer Epidemiology, International Agency for Research on Cancer, Lyon, France.

2 Division of Cancer Epidemiology and Genetics, National Cancer Institute, Bethesda, Maryland, United States.

3 Division of Occupational Medicine, Department of Public Health Science, Karolinska Institute, Stockholm, Sweden.

4 Department of Medical Epidemiology, Karolinska Institute, Stockholm, Sweden.

5 Department of Family Medicine, Karolinska Institute, Stockholm, Sweden.

Reprint requests to: Dr P Boffetta, Unit of Environmental Cancer Epidemiology, International Agency for Research on Cancer, 150 Cours Albert Thomas, FR-69008 Lyon, France. [E-mail: boffetta@iarc.fr] 
additional US cohort of dry cleaners and launderers (6). For bladder cancer, elevated risks were found in two cohorts of dry cleaners $(4,5)$ and two cohorts of dry cleaners and launderers $(6,7)$, but not in additional cohorts $(3,8,9)$. Increased risks have also been sporadically reported for cancers of the cervix uteri $(3-5,7)$, kidney $(3,4,7,8)$, lung $(3,4,8)$, intestine $(3,4)$, liver $(3,10)$, pancreas $(4,9)$, and larynx $(5,6)$, as well as for leukemia (3), Hodgkin's disease (5) and non-Hodgkin's lymphoma $(5,7)$.

Data from the Swedish censuses and national cancer registry provided the opportunity to study cancer incidence in a large population of launderers, dry cleaners, and pressers. The censuses contain information on both occupational title and industry at two points in time one decade apart and therefore provide an opportunity to define distinct occupational groups.

\section{Material and methods}

In 1960 and 1970, Statistics Sweden conducted two national population and housing censuses. Information was collected through questionnaires on place of residence, employment status, job title, and industry for all persons living in Sweden. The Swedish national cancer register, established in 1958, records all cases of malignant tumors among persons living in Sweden. The record linkage of the censuses in both 1960 and 1970, the Swedish national cancer register, and the national register of causes of death created the Cancer Environment Register III (CERIII). Thus the CERIII included cancer patients who were resident in Sweden both in 1960 and 1970. In order to allow the calculation of person-years at risk, a background register, with all the Swedish residents who took part in both the 1960 and 1970 censuses, was established. After the record linkages, the national registration numbers were removed from both the CERIII and the background register to ensure confidentiality. To ascertain cancer outcomes in these cohorts and their dates of diagnosis, the background register was linked to the CERIII, matching on all available census variables in both data sets (11).

In this study of cancer incidence among dry cleaning, laundering, and ironing workers, each cohort member contributed person-years of observation from 1 January 1971 until the first cancer diagnosis, death, or end of follow-up (31 December 1989), whichever occurred first; second primary neoplasms were excluded from the analyses. Subjects in the cohort were classified according to residence in one of four main regions of the country and residence in a large urban area (Stockholm, Gothenburg or Malmo) versus the rest of the country. We focused our interest on persons who, at the time of either census, worked as launderers, dry cleaners, or pressers (Nordic Classification of Occupation 943 for launderers and dry cleaners and 944 for pressers) or were employed in the laundry, ironing, or dyeing industry (Swedish industrial code 880 in 1960 and 9520 in 1970). People who retired between 1960 and 1971 were included in the cohort.

We defined four groups of exposed subjects (table 1). Persons classified with either a relevant occupational code or the relevant industrial code at the time of either census formed exposure group 1 (543036 person-years),

Table 1. Person-years by gender and occupational and industrial codes. [groups $2-4=$ exposure subgroups (see definition in the text), Unexposed = unexposed population (reference in multivariable regression), occupational code 943 = launderers and dry cleaners, occupational code 944 = pressers, industrial code 880 or 9520 = laundry, ironing or dyeing industry]

\begin{tabular}{|c|c|c|c|c|}
\hline \multirow{3}{*}{1970} & \multicolumn{4}{|c|}{1960} \\
\hline & \multicolumn{2}{|c|}{ Occupational code 943 or 944} & \multicolumn{2}{|c|}{ Other occupational code } \\
\hline & Industrial code 880 & Other industrial code & Industrial code 880 & Other industrial code \\
\hline \multicolumn{5}{|c|}{ Occupational code 943 or 944} \\
\hline \multicolumn{5}{|c|}{ Industrial code 9520} \\
\hline Women & 31418 Group 2 & 2496 & 2618 & 81496 \\
\hline Men & 15515 & 992 & 3268 & 15467 \\
\hline \multicolumn{5}{|c|}{ Other industrial code } \\
\hline Women & 3078 & 9609 Group 3 & 173 & 24261 \\
\hline Men & 636 & 9351 & 189 & 7475 \\
\hline \multicolumn{5}{|c|}{ Other occupational code } \\
\hline \multicolumn{5}{|c|}{ Industrial code 9520} \\
\hline Women & 3540 & 299 & 9205 & 43298 \\
\hline Men & 1605 & 228 & 4190 & 12845 \\
\hline \multicolumn{5}{|c|}{ Other industrial code } \\
\hline Women & 101121 & 51702 & 35943 & 28870832 \\
\hline Men & 17400 & 20915 & 32702 & 40669352 Unexpused \\
\hline
\end{tabular}


those employed as launderers, dry cleaners, or pressers in the laundry, ironing, or dyeing industry at the time of both censuses formed group 2 (46934 person-years), those employed in the relevant jobs but in other industries at the time of both censuses formed group 3 (18 960 person-years), and those in the laundry, ironing, or dyeing industry in jobs other than launderers, dry cleaners, or pressers at the time of both censuses formed group 4 (13395 person-years). The main industries of employment of the persons in group 3 were the readymade garment industry and the health care industry; the most common job titles for persons in group 4 were shop assistant, other sewing work, and driver. People in exposure group 2 were further divided into separate occupational groups of launderers and dry cleaners (occupational code 943) and pressers (occupational code 944) because the latter group was less likely to be exposed to solvents. People who did not work as dry cleaners, launderers, or pressers and were not employed in the laundry, ironing, or dyeing industry at the time of both censuses defined the unexposed population for all the analyses of employed persons (69540184 personyears).

Multivariable Poisson regression analyses were performed on the incidence of selected types of cancer in the exposed groups as compared with the unexposed employed population. Stratification variables (gender, 5-year age groups, 4-year calendar periods, residence regions, and urbanization levels) were introduced in the multivariable regression models. Relative risks (RR) and 95\% confidence intervals (95\% CI) were calculated by gender for each category of exposure. To assess the homogeneity of the gender-specific relative risk estimates, we compared the model with the gender $\times$ exposure interaction term with the model without this term. By subtracting the log likelihood of the model without the interaction from the log likelihood of the model with the interaction, we obtained a statistic that followed a chisquared distribution with one degree of freedom (12).

In order to assess temporal changes in solvent use, we conducted an analysis stratified by age at the time of the 1960 census, restricted to subjects employed as dry cleaners, launderers, or pressers in the laundry, ironing, or dyeing industry in that year. Before 1960, Stoddard solvent, carbon tetrachloride, and TCE were the predominant solvents used in dry cleaning, whereas after 1960 PCE became the most widely used solvent (TCE was still used to a limited extent in Europe, as was carbon tetrachloride, which was used for spot removal) (13). Therefore, persons aged 60 years or more in 1960 presumably used mainly Stoddard solvent, carbon tetrachloride, and TCE; those under 40 years of age in 1960 presumably used mainly PCE and carbon tetrachloride, possibly with some TCE, while those between 40 and 60 years of age in 1960 presumably used Stod- dard solvent, carbon tetrachloride, and TCE, but also PCE. To assess the homogeneity of the effect estimates calculated by birth cohort, we compared the model with birth cohort $\times$ exposure interaction terms with the model without these terms (difference in log likelihood as chi-square test with two degrees of freedom (12)).

For the sake of comparison with previous studies, cancer incidence in exposure group 2 was also compared with the cancer incidence of the national population through indirect standardization. We calculated standardized incidence ratios (SIR), defined as the ratio of the observed to the expected cases (14), for all neoplasms combined and for specific neoplasms. The expected numbers of cancers were obtained by applying the national rates stratified by gender, 5-year age group, and calendar year group to the cohort. Ninety-five percent confidence intervals (95\% CI) were calculated on the assumption that, under the null hypothesis, the observed number of cases follows a Poisson distribution. Second primary cancers were included in the calculation of both the observed and expected cases.

\section{Results}

Effect estimates for both genders combined are presented in table 2, both for exposure group 1 (ever employment in one of the relevant jobs or the industry at the time of either census) and for exposure group 2 (employment in both a relevant job and the industry at the time of both censuses). People in exposure group 1 showed an increased incidence of lung cancer [relative risk (RR) 1.15, 95\% CI 1.02-1.31], laryngeal cancer (RR 1.15, 95\% CI 0.73-1.81), stomach cancer (RR 1.12, 95\% CI 0.97-1.30), kidney cancer (RR $1.11,95 \%$ CI 0.93-1.33), and Hodgkin's disease (RR 1.35, 95\% CI 0.88-2.08), and the increased incidence was strengthened when the risk associated with exposure group 2 was examined. While the leukemia incidence was not elevated using the broad definition of exposure, there was a notably increased incidence for those in exposure group 2 (RR 1.84, 95\% CI 1.11-3.06), and it was primarily due to increases in chronic leukemia subtypes (chronic lymphocytic leukemia and chronic nonlymphocytic leukemia). Esophageal cancer incidence was elevated for exposure group 1 (RR 1.32, 95\% CI 0.94 1.85 ), but not for group 2 . Among the women, a significant excess of cervical cancer (RR 1.34, 95\% CI 1.121.60) was observed for exposure group 1, but not for group 2.

An examination of the gender-specific cancer incidence associated with exposure group 2 (employment as dry cleaners, launderers, or pressers in the laundry, ironing, or dyeing industry in both 1960 and 1970) (table 3) revealed some differences in cancer risk 
Table 2. Relative risks for cancer among all (male and female) the launderers, dry cleaners, and pressers employed in the laundry, ironing, or dyeing industry — results of the Poisson regression analysis. [RR = relative risk adjusted for age, calendar period, geographic region, urban setting and gender for relative risks calculated for both the men and the women (reference category $=$ never employed in relevant occupation or industry), $95 \% \mathrm{Cl}=95 \%$ confidence interval, group 1 = persons classified with either a relevant occupational code or the relevant industrial code at the time of one or both censuses, group $2=$ persons classified with either a relevant occupational code or the relevant industrial code at the time of both censuses]

\begin{tabular}{|c|c|c|c|c|c|c|}
\hline \multirow[t]{2}{*}{ Neoplasms } & \multicolumn{3}{|c|}{$\begin{array}{l}\text { Exposure group } 1 \text { in } \\
1960 \text { or } 1970\end{array}$} & \multicolumn{3}{|c|}{$\begin{array}{l}\text { Exposure group } 2 \text { in } \\
1960 \text { and } 1970\end{array}$} \\
\hline & Cases (N) & $\mathrm{RR}$ & $95 \% \mathrm{Cl}$ & Cases (N) & $\mathrm{RR}$ & $95 \% \mathrm{Cl}$ \\
\hline All cancers & 3742 & 0.95 & $0.92-0.98$ & 389 & 0.99 & $0.90-1.10$ \\
\hline Oral cavity & 65 & 0.98 & $0.77-1.25$ & 7 & 0.98 & $0.47-2.05$ \\
\hline Esophagus & 34 & 1.32 & $0.94-1.85$ & 1 & 0.34 & $0.05-2.39$ \\
\hline Stomach & 184 & 1.12 & $0.97-1.30$ & 22 & 1.32 & $0.87-2.01$ \\
\hline Colon & 295 & 1.00 & $0.89-1.12$ & 27 & 0.93 & $0.64-1.36$ \\
\hline Liver and biliary passages & 105 & 1.02 & $0.84-1.24$ & 13 & 1.26 & $0.73-2.18$ \\
\hline Pancreas & 133 & 1.12 & $0.95-1.33$ & 10 & 0.82 & $0.44-1.52$ \\
\hline Larynx & 19 & 1.15 & $0.73-1.81$ & 4 & 1.91 & $0.72-5.10$ \\
\hline Lung & 248 & 1.15 & $1.02-1.31$ & 30 & 1.20 & $0.84-1.72$ \\
\hline Cervix (women only) & 129 & 1.34 & $1.12-1.60$ & 9 & 1.09 & $0.57-2.09$ \\
\hline Prostate (men only) & 228 & 1.05 & $0.92-1.19$ & 34 & 1.27 & $0.91-1.78$ \\
\hline Kidney & 121 & 1.11 & $0.93-1.33$ & 14 & 1.20 & $0.71-2.02$ \\
\hline Bladder & 145 & 1.01 & $0.86-1.19$ & 16 & 1.00 & $0.61-1.63$ \\
\hline Non-Hodgkin's lymphoma & 85 & 0.94 & $0.76-1.16$ & 8 & 0.86 & $0.43-1.72$ \\
\hline Hodgkin's disease & 21 & 1.35 & $0.88-2.08$ & 4 & 2.69 & $1.01-7.19$ \\
\hline Leukemia & 86 & 1.06 & $0.85-1.31$ & 15 & 1.84 & $1.11-3.06$ \\
\hline Acute lymphocytic leukemia & 5 & 1.95 & $0.80-4.75$ & 0 &.$\cdot$ & $\cdot$ \\
\hline Chronic lymphocytic leukemia & 32 & 1.02 & $0.72-1.45$ & 6 & 1.85 & $0.83-4.12$ \\
\hline Acute nonlymphocytic leukemia & 23 & 0.95 & $0.63-1.44$ & 3 & 1.25 & $0.40-3.89$ \\
\hline Chronic nonlymphocytic leukemia & 13 & 1.15 & $0.66-1.98$ & 3 & 2.77 & $0.89-8.61$ \\
\hline
\end{tabular}

Table 3. Relative risks for cancer among the launderers, dry cleaners, and pressers employed in the laundry, ironing, or dyeing industry in 1960 and 1970 (exposure group 2) - results of the Poisson regression analysis stratified by gender. [RR = relative risk adjusted for age, calendar period, geographic region, and urban setting (reference category = never employed in relevant occupation or industry), $95 \% \mathrm{Cl}=95 \%$ confidence interval]

\begin{tabular}{|c|c|c|c|c|c|c|c|}
\hline \multirow[t]{2}{*}{ Neoplasms } & \multicolumn{3}{|c|}{ Women } & \multicolumn{3}{|c|}{ Men } & \multirow[b]{2}{*}{ P-value } \\
\hline & Cases (N) & $\mathrm{RR}$ & $95 \% \mathrm{Cl}$ & Cases $(\mathrm{N})$ & $\mathrm{RR}$ & $95 \% \mathrm{Cl}$ & \\
\hline All cancers & 252 & 1.01 & $0.90-1.15$ & 137 & 1.14 & $0.96-1.34$ & 0.05 \\
\hline Oral cavity & 4 & 1.25 & $0.47-3.35$ & 3 & 0.78 & $0.25-2.43$ & 0.60 \\
\hline Esophagus & 1 & 0.81 & $0.11-5.77$ & 0 & .. & . & 0.19 \\
\hline Stomach & 9 & 0.99 & $0.52-1.91$ & 13 & 1.80 & $1.05-3.11$ & 0.13 \\
\hline Colon & 18 & 0.90 & $0.56-1.42$ & 9 & 1.05 & $0.55-2.02$ & 0.66 \\
\hline Liver and biliary passages & 10 & 1.34 & $0.72-2.49$ & 3 & 1.15 & $0.37-3.56$ & 0.87 \\
\hline Pancreas & 6 & 0.73 & $0.33-1.63$ & 4 & 0.99 & $0.37-2.64$ & 0.64 \\
\hline Larynx & 0 & .. & . & 4 & 2.42 & $0.91-6.45$ & 0.17 \\
\hline Lung & 11 & 1.10 & $0.61-1.98$ & 19 & 1.36 & $0.87-2.14$ & 0.40 \\
\hline Kidney & 11 & 1.59 & $0.88-2.87$ & 3 & 0.62 & $0.20-1.93$ & 0.12 \\
\hline Bladder & 4 & 0.59 & $0.22-1.57$ & 12 & 1.32 & $0.75-2.32$ & 0.13 \\
\hline Non-Hodgkin's lymphoma & 3 & 0.52 & $0.17-1.61$ & 5 & 1.41 & $0.59-3.40$ & 0.16 \\
\hline Hodgkin's disease & 3 & 3.57 & $1.15-11.13$ & 1 & 1.58 & $0.22-11.26$ & 0.47 \\
\hline Leukemia & 12 & 2.53 & $1.44-4.46$ & 3 & 0.93 & $0.30-2.88$ & 0.10 \\
\hline Acute lymphocytic leukemia & 0 & .. & $\cdot$ & 0 & .. & $\cdot$ & .. \\
\hline Chronic lymphocytic leukemia & 5 & 2.89 & $1.20-6.96$ & 1 & 0.67 & $0.09-4.76$ & 0.13 \\
\hline Acute nonlymphocytic leukemia & 1 & 0.66 & $0.09-4.66$ & 2 & 2.42 & $0.61-9.69$ & 0.26 \\
\hline Chronic nonlymphocytic leukemia & 3 & 4.43 & $1.42-13.81$ & 0 &.. & $\cdot$ & 0.10 \\
\hline
\end{tabular}

a P-value of the test for the homogeneity of the RR among the men and women. 
between the genders. An increased incidence of leukemia was mainly due to an elevation among the women (RR 2.53, 95\% CI 1.44-4.46), as was the increase in kidney cancer incidence (RR 1.59, 95\% CI 0.88-2.87). On the other hand, elevated incidences of stomach (RR $1.80,95 \%$ CI 1.05-3.11) and laryngeal cancers (RR $2.42,95 \%$ CI $0.91-6.45$ ) were found for the men only. Despite these differences in results by gender, the homogeneity test failed to reach the significance level of $5 \%$ for any cancer site. The elevated relative risk estimates found for exposure group 2 using multivariable Poisson regression (table 3) were confirmed in the external comparison using the Swedish cancer rates (results not shown in tables). The increased estimate observed among the women for leukemia (SIR 2.24, 95\% CI 1.163.92) was the only statistically significantly increased risk in this analysis.

In the analyses of the risk associated with employment as launderers or dry cleaners versus pressers (results not shown in detail), the results for the first group reflected those of the whole exposure group (group 2) owing to their large contribution to this group (73\% of the person-years). A slightly lower relative risk of Hodgkin's disease (RR 1.78, 95\% CI 0.25-12.69) was observed for the men and women, while slightly higher risks were found for the men with respect to stomach cancer (RR 1.92, 95\% CI 1.09-3.38) and laryngeal cancer (RR 2.83, 95\% CI 1.06-7.54). The elevated estimate for leukemia among the women remained unchanged. The analysis of pressers was limited by the small number of exposed persons, but there was an increased lung cancer risk (6 cases, RR 1.67, 95\% CI 0.75-3.72) (not shown in detail).

Effect estimates for exposure group 3 (dry cleaners, launderers, and pressers employed in industries other than laundry, ironing or dyeing at the time of both censuses) were unremarkable, with the exception of the kidney cancer risk experienced by women (RR 2.71, 95\% CI 1.22-6.04) (results not shown in the tables).

Among persons in exposure group 4 (employed in the laundry, ironing, or dyeing industry, but not as dry cleaners, launderers, or pressers at the time of both censuses), nonsignificant excesses of about 1.6 for cervical and stomach cancers were noted for the women, while for the men elevated risks of esophageal cancer (RR 3.61, 95\% CI 0.90-14.42) and Hodgkin's disease (RR $11.38,95 \%$ CI $2.84-45.58$ ) were found (results not shown in the tables).

Figure 1 presents selected effect estimates by age group at the time of the 1960 census. Heterogeneous

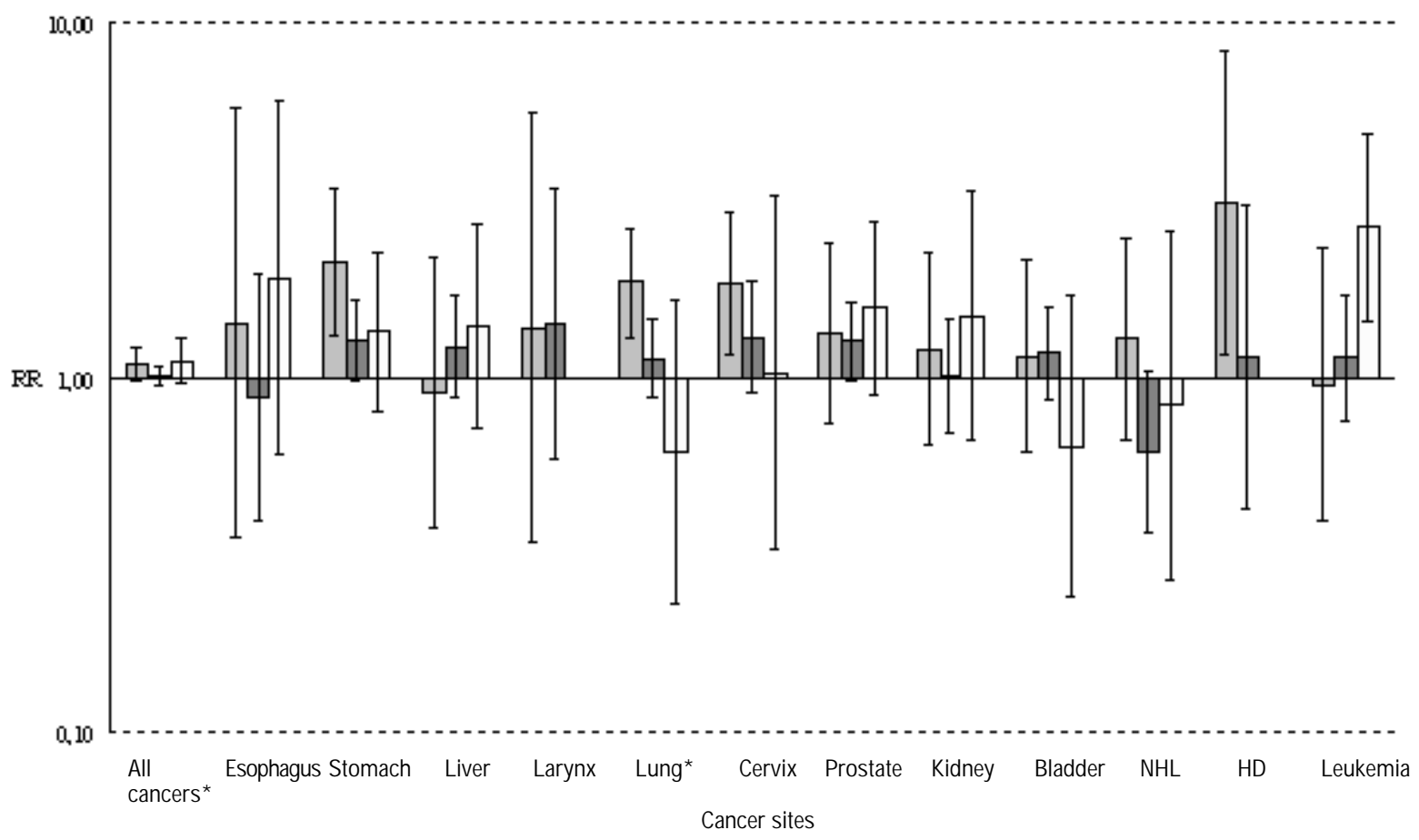

Age in $1960 \quad \square<40$ years $\square$ 40-59 years $\square>59$ years

Figure 1. Relative risk (RR) for the dry cleaners, launderers, and pressers employed in thelaundry, ironing or dyeing industry in 1960 by age group. ( ${ }^{*} \mathrm{P}<0.05$ for the homogeneity test between the age groups, $\mathrm{NHL}=$ non-Hodgkin's lymphoma, $\mathrm{HD}=$ Hodgkin's disease, $\mathrm{RR}=$ relative risk adjusted for gender, age, calendar period, geographic region and urban setting) 
estimates were found for the different birth age groups for all cancers combined and for lung cancer. Statistically significant increased risks were found for the subjects who were under 40 years of age for stomach, lung, and cervical cancers, as well as for Hodgkin's disease, while persons aged 60 years or more showed a statistically significant increase in leukemia incidence.

\section{Discussion}

For the launderers, dry cleaners, and pressers employed in the laundry, ironing, or dyeing industry both in 1960 and 1970 (exposure group 2), we found a significantly increased risk of Hodgkin's disease for both genders combined, a significantly elevated risk of leukemia for the women, and nonsignificantly elevated risks of lung cancer for both genders, kidney cancer for the women, and stomach, laryngeal and prostate cancers for the men. These observed increased risks were greater when the narrower exposure definition of exposure group 2 was compared with exposure group 1, suggesting that the observed associations may be due to employment in the jobs and industries of interest. While the pattern of the results observed for some cancers differed somewhat between the men and women, the hypothesis of homogeneity was not formally rejected for any cancer. The low power of the statistical tests of heterogeneity may explain why the results of the men and women did not appear to be heterogeneous, while differences in the exposure circumstances of the men and women holding the same job title may explain the observed differences (15).

Our present study overlapped somewhat with two previous studies in which the results concerning dry cleaners were reported as part of a systematic review of occupation-cancer associations $(16,17)$. The first (16) presented summary results on cancer incidence between 1971 and 1989 for persons employed as launderers, dry cleaners, or pressers in Sweden at the time of the 1970 census. In the second study (17), also based on cancer incidence follow-up between 1971 and 1989, separate risks were calculated for those in the occupation in 1970 and those in the occupation at the time of both the 1960 and 1970 censuses. However, this report only presented statistically increased standardized incidence ratios, and only a few results were reported for launderers and dry cleaners and even fewer for pressers. Our present study pays more attention to the credibility of observed associations and to the possible role of solvents by presenting more-detailed analyses in which the opportunity for relevant occupational exposures is explored using different approaches, based on combinations of occupational and industrial codes, and by looking at different birth cohorts.
There are inherent limitations in using self-reported occupational and industrial codes to classify exposure, namely, the possible misclassification of occupational and industrial titles and the lack of information on job tasks and exposure to specific agents. By creating more specific exposure groups based on both occupation and industry, we have addressed, to some extent, the first concern; nevertheless, exposure assessment based on occupational and industrial codes remains but a surrogate for specific information on occupational carcinogens. In 1990 only $35 \%$ of Swedish PCE users and $23 \%$ of TCE users were employed in the dry cleaning and laundering industry (18); furthermore, in 1970, only $30 \%$ of Swedish dry cleaners and launderers reported handling solvents (19). This last result may be explained by the lower prevalence of solvent exposure for launderers as compared with dry cleaners. It should be stressed, however, that these sources of exposure misclassification act in prospective studies nondifferentially with respect to outcome; their effect is therefore likely to be an underestimation of risk estimates.

An additional limitation of our study is the lack of information on potential confounding factors, such as tobacco smoking, alcohol drinking, and other life-style factors. For tobacco smoking and alcohol drinking we have arguments detracting from the plausibility of confounding. We did not observe any consistently increased risk of esophageal and bladder cancers, two neoplasms clearly associated with tobacco smoking (20, 21), and for esophageal cancer alcohol drinking (20). Furthermore, confounding by smoking is not likely to explain the difference in lung cancer risk observed according to age at the time of the 1960 census (figure 1).

An increased risk for esophageal cancer was an a priori hypothesis, because the three previous cohort studies found an excess of this neoplasm (4-6), as did a case-referent study from the United States (22). However, we did not observe a consistent increase in the risk of esophageal cancer in our study. Neither could we confirm the excess risk of bladder cancer observed in US cohort studies of dry cleaners $(4,5)$, and in US and Canadian case-referent studies of nonwhite dry cleaners, ironers, and pressers (23) and laundry personnel (24). Our negative results may be explained by differences in exposure circumstances between North America and Sweden, as well as by dilution due to the inclusion of launderers, who have less solvent exposure than dry cleaners.

We observed an increased risk of lung cancer among dry cleaners, launderers, and pressers and employees of the laundry, ironing, and dyeing industries, a finding that corroborated those of three previous cohort studies (3, $4,8)$ and two case-referent studies $(25,26)$. This excess was highest among the persons below 40 years of age in 1960, and it may reflect a carcinogenic effect of 
solvents used in late time periods, such as PCE and TCE. We found an increased risk of laryngeal cancer among men, the power of this analysis among women being modest. An increased risk of this neoplasm has been reported in two previous cohort studies $(5,6)$ and in one case-referent study (22).

A unifying mechanistic hypothesis for an excess of esophageal, laryngeal, and lung cancers is that solvent exposure in the dry cleaning industry potentiates the carcinogenic effect of tobacco smoke, similar to the effect of alcohol in cancers of the upper aerodigestive tract (27).

The excess of stomach cancer observed in this study among the men who worked as dry cleaners, launderers, or pressers at the time of both censuses was mainly due to an elevated number of cancers arising from the cardia (5 cases, RR 6.09, 95\% CI 2.53-14.67). This finding was unexpected, even though a linkage study conducted in Norway (16) found a significant increase of stomach cancer among men. A small excess was also found in a cohort study considering men and women together (3), the other cohort studies having reported nonsignificant stomach cancer deficits $(5,7,8,28)$. Nevertheless, as no reports in the literature have associated stomach cancer with organic solvent exposure, the association found in our study may have been due to chance.

The observed increase in kidney cancer incidence among women corroborates findings from previous cohort studies $(3,4,7,8)$. The evidence of an association between TCE or PCE exposure and kidney cancer is inconclusive (29). At least in one study, however, an increased risk of renal cell cancer was associated with TCE exposure among women, but not among men (15). It is also possible that the association observed in our study may have been due to occupational exposures other than solvents, as the risk was highest for female dry cleaners, launderers, and pressers employed in industries other than laundry, ironing, and dyeing.

An increased risk of cervical cancer was observed in our study population; however, the fact that no increase was present among women employed at the time of both censuses in the relevant jobs and industries detracts from a causal interpretation.

A small excess of Hodgkin's disease was observed in our study, with a particularly striking result for the women in exposure group 2. An excess of Hodgkin's disease has been reported previously for a US cohort of dry cleaners (5). In linkage studies of women from Nordic countries working as launderers or dry cleaners, increased risks were found in Denmark and Norway, but not in Finland (16). Nevertheless, since a misclassification of Hodgkin's and non-Hodgkin's lymphomas has been described in Sweden (30, 31), our results should be interpreted cautiously. The elevated risk was observed particularly among the subjects who were below 40 years of age in 1960, who used mainly PCE with possibly some TCE.

An increase in leukemia risk has been reported for American dry cleaners and launderers (3), but this result contrasts with deficits observed in other cohort studies of either dry cleaners and launderers $(7,9)$ or dry cleaners only $(5,28)$. In our study, the risk of leukemia was primarily increased in the earlier birth cohort (11 cases, RR 2.66, 95\% CI 1.46-4.84), pointing towards solvents such as TCE, carbon tetrachloride, and benzene as possible leukemogenic agents.

In conclusion, we identified an elevated risk of certain digestive, respiratory, and lymphohematopoietic neoplasms among Swedish workers registered as dry cleaners, launderers, or pressers in the laundry, ironing, or dyeing industry. If they are not due to chance or confounding, these associations could be explained either by potentiation of other carcinogens by solvents or by direct effects.

\section{Acknowledgments}

We would like to thank Aaron Blair and Patricia Hartge of the National Cancer Institute and Sarah Lewis from the International Agency for Research on Cancer for their helpful comments on the manuscript. We are also very grateful to Heather Clancy of the Information Management Services for the computer programming.

\section{References}

1. IARC Working Group. Dry cleaning, some chlorinated solvents and other industrial chemicals. Lyon: International Agency for Research on Cancer (IARC), 1995. IARC monographs on the evaluation of the carcinogenic risks to humans, vol 63.

2. Echeverria D, White RF, Sampaio C. A behavioral evaluation of PCE exposure in patients and dry cleaners: a possible relationship between clinical and preclinical effects. J Occup Environ Med 1995;37:667-80.

3. Blair A, Decoufle P, Grauman D. Causes of death among laundry and dry cleaning workers. Am J Public Health 1979; 69:508-11.

4. Ruder AM, Ward EM, Brown DP. Mortality in dry-cleaning workers: an update. Am J Ind Med 2001;39:121-32.

5. Blair A, Stewart PA, Tolbert PE, Grauman D, Moran FX, Vaught J, et al. Cancer and other causes of death among a cohort of dry cleaners. Br J Ind Med 1990;47:162-8.

6. Walker JT, Burnett CA, Lalich NR, Sestito JP, Halperin WE. Cancer mortality among laundry and dry cleaning workers. Am J Ind Med 1997;32:614-9.

7. Katz RM, Jowett D. Female laundry and dry cleaning workers in Wisconsin: a mortality analysis. Am J Public Health 
1981;71:305-7.

8. Duh RW, Asal NR. Mortality among laundry and dry cleaning workers in Oklahoma. Am J Public Health 1984;74:127880 .

9. Lynge E, Thygesen L. Primary liver cancer among women in laundry and dry-cleaning work in Denmark. Scand J Work Environ Health 1990;16:108-12.

10. Lynge E. Danish Cancer Registry as a resource for occupational research. J Occup Med 1994;36:1169-73.

11. Moradi T, Nyren O, Bergstrom R, Gridley G, Linet M, Wolk $\mathrm{A}$, et al. Risk for endometrial cancer in relation to occupational physical activity: a nationwide cohort study in Sweden. Int J Cancer 1998;76:665-70.

12. Breslow NE, Day NE. Statistical methods in cancer research; vol 1 (The analysis of case-control studies). Lyon: International Agency for Research on Cancer (IARC), 1980. IARC scientific publications, no 32 .

13. McGregor DB, Heseltine E, Moller H. Dry cleaning, some solvents used in dry cleaning and other industrial chemicals [meeting report]. Scand J Work Environ Health 1995;21:310 12.

14. Breslow NE, Day NE. Statistical methods in cancer research; vol II (The design and analysis of cohort studies). Lyon: International Agency for Research on Cancer (IARC), 1987. IARC scientific publications, no 82.

15. Dosemeci M, Cocco P, Chow WH. Gender differences in risk of renal cell carcinoma and occupational exposures to chlorinated aliphatic hydrocarbons. Am J Ind Med 1999;36:54-9.

16. Andersen A, Barlow L, Engeland A, Kjaerheim K, Lynge E, Pukkala E. Work-related cancer in the Nordic countries. Scand J Work Environ Health 1999;25 suppl 2:1-116.

17. Pollan M, Gustavsson P. Cancer and occupation in Sweden 1971-1989. Stockholm: Socialstyrelsen; The National Board of Health and Welfare; Yrkesmedicin, 1999. Center for Epidemiology (EpC) repport 1999:1.

18. Plato N, Kauppinen T, Toikkanen J, Pedersen D, Young R, Kogevinas M. Occupational exposure to carcinogens in Sweden in 1990-93: preliminary results. Helsinki: Finnish Institute of Occupational Health, 1998.

19. Lundberg I. Occupation and cancer. In: Jarvholm B, editor. Working life and health: a Swedish survey. Solna (Sweden): Arbetslivsinstitutet; (National Institute of Working Life) 1998:59.
20. Munoz N, Day NE. Esophageal cancer. In: Schottenfeld D, Fraumeni JF, editors. Cancer epidemiology and prevention. 2nd ed. Oxford: Oxford University Press, 1996:681.

21. Silverman DT, Morrison AS, Devesa SS. Bladder cancer. In: Schottenfeld D, Fraumeni JF, editors. Cancer epidemiology and prevention. 2nd ed. Oxford: Oxford University Press, 1996:1156.

22. Vaughan TL, Stewart PA, Davis S, Thomas DB. Work in dry cleaning and the incidence of cancer of the oral cavity, larynx, and oesophagus. Occup Environ Med 1997;54:692-5.

23. Silverman DT, Levin LI, Hoover RN. Occupational risks of bladder cancer in the United States: II Nonwhite men. J Natl Cancer Inst 1989;81:1480-83.

24. Teschke K, Morgan MS, Chekoway H, Franklin G, Spinelli JJ, van Belle G, et al. Surveillance of nasal and bladder cancer to locate sources of exposure to occupational carcinogens. Occup Environ Med 1997;54:443-51.

25. Pohlabeln H, Boffetta P, Ahrens W, Merletti F, Agudo A, Benhamou E, et al. Occupational risks for lung cancer among non-smokers. Epidemiology 2000;11:532-8.

26. Brownson RC, Alavanja MCR, Chang JC. Occupational risk factors for lung cancer among nonsmoking women: a casecontrol study in Missouri (United States). Cancer Causes Control 1993;4:449-54.

27. Hsu TC, Furlong C, Spitz MR. Ethyl alcohol as a cocarcinogen with special reference to the aerodigestive tract: a cytogenetic study. Anticancer Res 1991;11:1097-101.

28. Ruder AM, Ward EM, Brown DP. Cancer mortality in female and male dry-cleaning workers. J Occup Med 1994;36:86774.

29. McLaughlin JK, Blot WJ. A critical review of epidemiology studies of trichloroethylene and perchloroethylene and risk of renal-cell cancer. Int Arch Occup Environ Health 1997; 70:222-31.

30. Martinsson U, Glimelius B, Sundstrom C. Lymphoma incidence in a Swedish county during 1969-1987. Acta Oncol 1992;31:275-82.

31. Dige U, Johansson H, Lenner P, Norberg B, Roos G. Hodgkin's disease in northern Sweden 1971-1981, I: a histopathological reevaluation of 223 cases. Acta Oncol 1991;30:5936.

Received for publication: 6 March 2002 